\title{
Pattern of tobacco use among the Iranian adult population: results of the national Survey of Risk Factors of Non-Communicable Diseases (SuRFNCD-2007)
}

\author{
Alipasha Meysamie, ${ }^{1}$ Reza Ghaletaki, ${ }^{1}$ Mehrdad Haghazali, ${ }^{2}$ Fereshteh Asgari, ${ }^{2}$ \\ Armin Rashidi, ${ }^{3}$ Omid Khalilzadeh, ${ }^{3}$ Alireza Esteghamati, ${ }^{3}$ Mehrshad Abbasi ${ }^{3,4}$
}

\begin{abstract}
Department of Community and Preventive Medicine, Faculty of Medicine, Tehran University of Medical Sciences/university of Tehran, Tehran, Iran

${ }^{2}$ Centre for Disease Control and Management, Tehran, Iran

${ }^{3}$ Endocrinology and Metabolism Research Centre, Department of Endocrinology, Vali-asr Hospital, Tehran University of Medical Sciences/University of Tehran Tehran, Iran

${ }^{4}$ Nuclear Medicine Research Center, Shariati Hospital, Tehran University of Medical

Sciences/University of Tehran, Tehran, Iran
\end{abstract}

\section{Correspondence to}

Dr Mehrshad Abassi, Endocrine Research Center, Valiasr Hospital, Tehran University of Medical Sciences, Keshavarz Blvd, Tehran 14197-33147, Iran; abbasimsh@razi.tums.ac.ir

Received 2 April 2009 Accepted 18 November 2009

\section{(2) UNLOCK:}

This paper is freely available online under the BMJ Journals unlocked scheme, see http:// tobaccocontrol.bmj.com/site/ about/unlocked.xhtml

\section{ABSTRACT}

Background Previous studies report on smoking in Iran but recent national data on tobacco use (including cigarette, water-pipe and pipe) have not been reported. Methods In 2007, 5287 Iranians aged 15-64 years were sampled from all provinces as part of a national cross-sectional survey of non-communicable disease (NCD) risk factors. Data were collected using the standardised stepwise protocol for NCD risk factor surveillance of the World Health Organization. Use of tobacco products was calculated as the sum of smoking cigarettes/cigars (smoking currently or daily any amount of factory/hand-made cigarettes or cigars), pipes (daily) and water pipes (daily).

Results Total current and daily tobacco use was $14.8 \%$ (burden 7.3 million) and 13.7\% (burden 6.7 million) when extrapolated to the Iranian population aged 15-64. The prevalence of current and daily cigarette smoking was $12.5 \%$ (6.1 million; $23.4 \%$ males and 1.4\% females) and $11.3 \%$ (5.6 million; 21.4 males and 1.4 females); former smokers comprised 1.7 million or $3.4 \%$ of the Iranian population $(6.2 \%$ males and $0.6 \%$ females; mean cessation age 34.1$)$. The mean age of starting to smoke was 20.5 years (24.2 males and 20.4 females). The prevalence of water-pipe smoking was $2.7 \%$ (burden 1.3 million; $3.5 \%$ males and $1.9 \%$ females). Water-pipe smokers used the water-pipe on average 3.5 times a day (2.8 males and 4.5 females).

Conclusion The prevalence of tobacco use has not escalated over the past two decades. Nonetheless, the burden is high and therefore warrants preventive public health policies.

Tobacco use is one of the major preventable causes of premature death around the world. ${ }^{1}$ Ninety per cent of all lung cancers, $70 \%$ of chronic bronchitis and emphysema and about $25 \%$ of ischaemic heart events have been attributed to cigarette smoking. ${ }^{2}$ Among 4000 chemicals detected in tobacco smoke, 60 are known or suspected to be carcinogens. ${ }^{2}$

According to the World Health Orgnization, tobacco use in the 20th century resulted in 100 million deaths worldwide. Approximately 5 million deaths a year are attributed to tobacco, and this is projected to exceed one billion by the end of 21 st century. ${ }^{3}$ Approximately $70 \%$ of these deaths will occur in developing countries. ${ }^{4}$

Developing nations embrace a disproportionate share of the global tobacco burden ( $84 \%$ of all current smokers), comprising 1.3 billion individ- uals. ${ }^{1}$ Recent prevalence estimates for low and middle-income countries are 49\% for men and $8 \%$ for women. ${ }^{5}$ In addition, the harmful effects of passive smoking affect those people around smokers. $^{67}$

To decrease the prevalence of tobacco use and to eliminate its related dangers, it is necessary to have a general view of the current condition. The purpose of this article is to demonstrate the extent of tobacco smoking in Iran in different strata of age, sex and residential area based on information from the third national Surveillance of Risk Factors of Non-Communicable Diseases (SuRFNCD, 2007).

\section{METHODS}

The third national SuRFNCD in Iran, designed based on the STEPwise guidelines of WHO, was conducted in May 2007 and involved 5287 Iranian citizens. ${ }^{8}$ This survey was approved by the ethics committee of the Center for Disease Management of Iran. The survey sampling was based on random clusters of 10 males and 10 females living in neighbouring households. The address of the first subject of each cluster was selected from the list of postal addresses of the Iran Post Company. The households were approached based on a predetermined plan. Sampling was continued until 20 volunteers were registered. The study population included noninstitutionalised Iranian citizens aged 15-64 years. The survey sample was selected proportional to urban/rural population size of all 30 provinces of Iran. Participants were visited at their household by trained interviewers. Oral informed consent was obtained from participants.

Interviewers administered questionnaires containing six different domains: identification and demographic information, diet, physical activity, tobacco use, history of hypertension and history of diabetes. The tobacco-related questions of the STEPwise Approach to Chronic Disease Risk Factor Surveillance are built on the WHO guidelines for tobacco use surveillance documents. In brief, respondents were asked about current and daily use of any amount of any tobacco products including cigarettes, pipes and water-pipes. Tobacco use by pipe and 'chopoq', a smoking instrument similar to a pipe, was addressed in one question. Current cigarette smoking was defined as smoking any amount of any kind of factory-made cigarettes, hand-made cigarettes or cigars at the time of the interview. The 'current cigarette smokers' who 
Table 1 Estimates of current and daily tobacco smoking, Iran, 2007

\begin{tabular}{|c|c|c|c|c|c|c|}
\hline \multirow[b]{2}{*}{ Variable } & \multirow[b]{2}{*}{ Subcategory } & \multirow[b]{2}{*}{$\begin{array}{l}\text { Population } \\
\text { size ('000s) }\end{array}$} & \multicolumn{2}{|c|}{ Current tobacco use } & \multicolumn{2}{|c|}{ Daily tobacco use } \\
\hline & & & Burden & $\begin{array}{l}\text { Prevalence }(95 \% \\
\text { Cl) }\end{array}$ & Burden & $\begin{array}{l}\text { Prevalence }(95 \% \\
\text { CI) }\end{array}$ \\
\hline \multirow[t]{5}{*}{ Age } & $15-24$ & 17710 & 1608050 & $9.1 \%(6.8$ to 11.9$)$ & 1466850 & $8.3 \%(6.3$ to 10.8$)$ \\
\hline & $25-34$ & 12760 & 1833050 & $14.4 \%(11.6$ to 17.7$)$ & 1706950 & $13.4 \%(10.7$ to 16.6$)$ \\
\hline & $35-44$ & 9000 & 2014100 & $22.4 \%(17.3$ to 28.4$)$ & 1821900 & $20.2 \%(16.0$ to 25.3$)$ \\
\hline & $45-54$ & 6270 & 1314200 & $21.0 \%(17.1$ to 25.4$)$ & 1277900 & $20.4 \%$ (16.6 to 24.8$)$ \\
\hline & $55-64$ & 3350 & 501600 & $15.0 \%(12.0$ to 18.5$)$ & 462750 & $13.8 \%(11.0$ to 17.2$)$ \\
\hline \multirow[t]{2}{*}{ Sex } & Male & 24840 & 6487000 & $26.1 \%(23.8$ to 28.6$)$ & 6025000 & $24.3 \%(22.1$ to 26.6$)$ \\
\hline & Female & 24250 & 784000 & $3.2 \%(2.6$ to 4.0$)$ & 711400 & $2.9 \%(2.4$ to 3.6$)$ \\
\hline \multirow[t]{2}{*}{ Residential area } & Urban area & 34520 & 5031000 & $14.6 \%(11.8$ to 17.9$)$ & 4668250 & $13.5 \%(10.9$ to 16.7$)$ \\
\hline & Rural area & 14570 & 2240000 & $15.4 \%(10.1$ to 22.7$)$ & 2068150 & $14.2 \%(9.5$ to 20.6$)$ \\
\hline TOTAL & & 49090 & 7271000 & $14.8 \%(12.2$ to 17.9$)$ & 6736400 & $13.7 \%(11.3$ to 16.5$)$ \\
\hline
\end{tabular}

smoked daily, were defined as 'daily cigarette smokers'. Waterpipe and pipe/chopogh smokers were asked if they were daily habits. All measures considering overlaps were summed to estimate an overall prevalence of tobacco smoking. Respondents were also asked about history of daily use of any amount of cigarettes and cigars. Smoking cessation was inferred from this variable and comprised subjects who had been smoking any type of cigarettes (factory-made cigarettes, hand-made cigarettes or cigars) earlier, but they didn't smoke at the time of the study. Finally the extent and age of initiation and abstinence of tobacco product use were recorded if indicated.

\section{Statistical analysis}

Complex sample survey analyses were performed by SPSS 16 for Windows. To extrapolate the results to the Iranian adult population, data were weighted directly to the 2006 population of Iran aged $\geq 15$ years and $\leq 64$ years, based on the 2006 national Iranian census, to match the age (10-year strata), sex and area of residence (rural/urban). Prevalence rates are presented with 95\% CIs. Means of variables also are expressed with $95 \%$ CIs. ORs are reported where appropriate. All comparisons with external data were performed using $95 \%$ CIs. The burden of cigarette smoking was calculated by weighting the sample to the 15-64-year-old population of the country (Iran census 2006).

\section{RESULTS}

The total adult population of the country at the time of the study was about 49 million individuals aged 15-64 with 36\% between 15 years and 24 years of age.

National estimate of prevalence rates of current tobacco smoking (including cigarette smoking, water-pipe and pipe) was
$14.8 \%$ overall, $26.1 \%$ for men and $3.2 \%$ among women (table 1 ). Prevalence was highest among respondents aged 35-44 (22.4\%).

The prevalence of current cigarette smoking was $12.5 \%(95 \%$ CI $10.0 \%$ to $15.6 \%$ ), which corresponds to more than 6.1 million Iranians aged 15-64 (table 2). The highest prevalence of current cigarette smoking was in individuals aged 35-44 years (19.9\%). Males had much higher rates of current cigarette smoking than females $(23.4 \%$ (95\% CI $21.2 \%$ to $25.8 \%$ ) vs $1.4 \%$ (95\% CI $1.0 \%$ to $2.0 \%) ; \mathrm{OR}=21.5$ (95\% CI 16.2 to 27.9$)$ ). Current cigarette smoking was found in $12.7 \%$ and $12.1 \%$ of residents in urban and rural areas, respectively ( $\mathrm{OR}=1.1$ (95\% CI 0.9 to 2.0$)$ ). About $90.5 \%$ of current smokers were daily smokers $(11.3 \%$ of the total adult population (95\% CI $9.0 \%$ to $14.1 \%$ ), representing 5570000 Iranians). Less than $5 \%$ of respondents (3.4\%; $95 \%$ CI $2.7 \%$ to $4.3 \%$ ) were former smokers, representing 1680000 Iranians. The prevalence of former smokers was highest in those aged 55-64 (7.9\%).

In all, $2.7 \%(95 \%$ CI 2.2 to 3.4$)$ or 1341000 Iranians were daily water-pipes users and $0.3 \%$ (95\% CI 0.2 to $0.5 ; 152000$ Iranians) smoked tobacco by chopoq or pipe (table 3 ). More than half of tobacco smoking women (ie, $1.9 \%$ of overall $3.2 \%$ ) smoke tobacco employing water-pipe. Females do not use pipes to smoke.

On average 13.7 cigarettes were smoked per day among daily smokers (95\% CI 12.1 to 15.3 ) (table 4). Daily water-pipe smoking individuals smoked on average 3.5 times a day $(95 \% \mathrm{CI}$ 1.8 to 5.2). Pipe and chopoq daily tobacco smokers smoked 2.2 times a day on average ( $95 \%$ CI 0.8 to 3.6 ).

The mean age of starting to smoke was 20.4 (95\% CI 19.7 to 21.0 ) years in males, 24.2 (95\% CI 21.8 to 26.7 ) years in females, and 20.5 (95\% CI 19.9 to 21.2 ) overall (table 4). The age of first smoking experience is almost the same in urban and rural areas

Table 2 Estimates of current and daily cigarette smoking, Iran, 2007

\begin{tabular}{|c|c|c|c|c|c|c|c|}
\hline \multirow[b]{2}{*}{ Variable } & \multirow[b]{2}{*}{ Subcategory } & \multicolumn{2}{|c|}{ Current cigarette smoking } & \multicolumn{2}{|c|}{ Daily cigarette smoking } & \multicolumn{2}{|c|}{ Smoking cessation } \\
\hline & & Burden & $\begin{array}{l}\text { Prevalence }(95 \% \\
\text { CI) }\end{array}$ & Burden & $\begin{array}{l}\text { Prevalence (CI } \\
95 \% \text { ) }\end{array}$ & Burden & $\begin{array}{l}\text { Prevalence }(95 \% \\
\text { Cl) }\end{array}$ \\
\hline \multirow[t]{4}{*}{ Age } & $15-24$ & 1181000 & $6.7 \%$ (4.8 to 9.1$)$ & 1019050 & $5.8 \%$ (4.2 to 7.9 ) & 158450 & $0.9 \%(0.5$ to 1.7$)$ \\
\hline & $35-44$ & 1791020 & $19.9 \%$ (14.8 to 26.2 ) & 1591100 & $17.7 \%(13.4$ to 23.0$)$ & 425400 & $4.7 \%(3.4$ to 6.6$)$ \\
\hline & $45-54$ & 1151020 & $18.4 \%(14.4$ to 23.1$)$ & 1109040 & $17.7 \%$ (13.8 to 22.3$)$ & 434650 & $6.9 \%(5.1$ to 9.4$)$ \\
\hline & $55-64$ & 448250 & $13.4 \%(10.5$ to 17.0$)$ & 406010 & $12.1 \%(9.3$ to 15.6$)$ & 264860 & $7.9 \%(6.0$ to 10.4$)$ \\
\hline \multirow[t]{2}{*}{ Residential area } & Urban area & 4394150 & $12.7 \%(10.0$ to 16.1$)$ & 4010100 & $11.6 \%(9.014 .8)$ to & 1250400 & $3.6 \%(2.8$ to 4.7$)$ \\
\hline & Rural area & 1760150 & $12.1 \%(7.3$ to 19.4$)$ & 1559100 & $10.7 \%(6.6$ to 17.0$)$ & 428400 & $2.9 \%(1.8$ to 4.8$)$ \\
\hline TOTAL & & 6154300 & $12.5 \%(10.0$ to 15.6$)$ & 5569200 & $11.3 \%$ (9.0 to 14.1$)$ & 1678800 & $3.4 \%(2.7$ to 4.3$)$ \\
\hline
\end{tabular}


Table 3 Estimates of current use of water-pipe and of pipe/chopoq, Iran, 2007

\begin{tabular}{|c|c|c|c|c|c|}
\hline \multirow[b]{2}{*}{ Variable } & \multirow[b]{2}{*}{ Subcategory } & \multicolumn{2}{|c|}{ Current use of water-pipe } & \multicolumn{2}{|c|}{$\begin{array}{l}\text { Current use of pipe and } \\
\text { chopoq }\end{array}$} \\
\hline & & Burden & $\begin{array}{l}\text { Prevalence } \\
(95 \% \mathrm{CI})\end{array}$ & Burden & $\begin{array}{l}\text { Prevalence } \\
(95 \% \mathrm{CI})\end{array}$ \\
\hline \multirow[t]{5}{*}{ Age } & $15-24$ & 489710 & $2.8 \%(1.8$ to 4.1$)$ & 39700 & $0.2 \%(0.1$ to 0.9$)$ \\
\hline & $25-34$ & 338520 & $2.7 \%$ (1.9 to 3.7$)$ & 36150 & $0.3 \%(0.1$ to 0.9$)$ \\
\hline & $35-44$ & 266250 & $3.0 \%(2.2$ to 3.9$)$ & 64300 & $0.7 \%(0.3$ to 1.6$)$ \\
\hline & $45-54$ & 173120 & $2.8 \%(1.9$ to 4.0$)$ & 5655 & $0.1 \%(0.0$ to 0.7$)$ \\
\hline & $55-64$ & 73300 & $2.2 \%$ (1.5 to 3.3$)$ & 6675 & $0.2 \%(0.0$ to 0.8$)$ \\
\hline \multirow[t]{2}{*}{ Sex } & Male & 876350 & $3.5 \%(2.7$ to 4.7$)$ & 140400 & $0.6 \%(0.3$ to 0.9$)$ \\
\hline & Female & 464550 & $1.9 \%(1.4$ to 2.5$)$ & 12080 & $0.0 \%(0.0$ to 0.4$)$ \\
\hline \multirow{2}{*}{$\begin{array}{l}\text { Residential } \\
\text { area }\end{array}$} & Urban & 763100 & $2.2 \%$ (1.7 to 2.8 ) & 114300 & $0.3 \%(0.2$ to 0.6$)$ \\
\hline & Rural & 577800 & $4.0 \%(3.0$ to 5.3$)$ & 38180 & $0.3 \%(0.1$ to 0.9$)$ \\
\hline TOTAL & & 1340900 & $2.7 \%(2.2$ to 3.4$)$ & 152480 & $0.3 \%(0.2$ to 0.5$)$ \\
\hline
\end{tabular}

(20.7 (95\% CI 20.1 to 21.3 ) years and 20.1 (95\% CI 18.3 to 21.9 ) years, respectively). Smoking cessation occurred on average at the age of 34.1 years (33.6 (95\% CI 31.6 to 35.7 ) in men and 42.0 years ( $95 \%$ CI 35.5 to 48.5 ) in women).

\section{DISCUSSION}

Cigarette smoking is the most popular form of smoking tobacco among Iranian men. However, among Iranian women use of water-pipe is the most common form of tobacco consumption. The age of smoking initiation is lower in men. Furthermore the number of cigarettes smoked a day is more in men compared to women. The amount increases by increasing age and peaks in people aged 45-64. Nevertheless, attempts to stop smoking happen earlier in men than in women. Although men start smoking earlier than women, earlier abstinence put men into equal or less risk associated with duration of exposure compared to women (duration of exposure is 17.8 years for women vs 13.2 years for men).

Cigarette consumption is a stigma for women in Iranian culture. Thus there is probably some under-reporting about smoking by females. According to a study done in an urban area of Iran to compare self-reported and biochemically indicated rates of tobacco use (by serum levels of cotinine) there was a significant difference between the two measures among women $(1.3 \%$ vs $6.7 \%){ }^{9}$

The most recent reported prevalence of current tobacco smoking among Iranian adults aged 15-64 was $14.2 \%$ in 2005 (24.1\% for men and $4.3 \%$ for women) according to $\mathrm{WHO}$ in the MPOWER package; the prevalence of daily tobacco smoking was $11.9 \%$ for the total population $(20.9 \%$ for men and $2.9 \%$ for women). ${ }^{3}$ Therefore, the prevalence of tobacco smoking has remained almost the same among Iranians from 2005 to 2007. The burden of current tobacco use in 2005 was approximately 7 million and the number of daily tobacco smokers was about 5897000 . The burden of current tobacco smoking in our study is about 7270000 (95\% CI 5370000 to 9372000 ) of whom 6737000 (95\% CI 4823000 to 8650000$)$ are daily tobacco users (table 1). Consequently, based on the CIs, no significant change has occurred during these 2 years.

In the earliest national survey on tobacco smoking in Iran (1991) cigarette smoking prevalence among Iranians aged 15-69 was $14.6 \%$ (27.2\% for males and 3.4\% for females). In 1999, cigarette smoking prevalence decreased to $11.7 \%$ (24\% for males and $1.5 \%$ for females). ${ }^{10}$ Compared to estimates from the current study we infer there is a slight decrease in the prevalence of cigarette smoking from 1991, with no significant change from

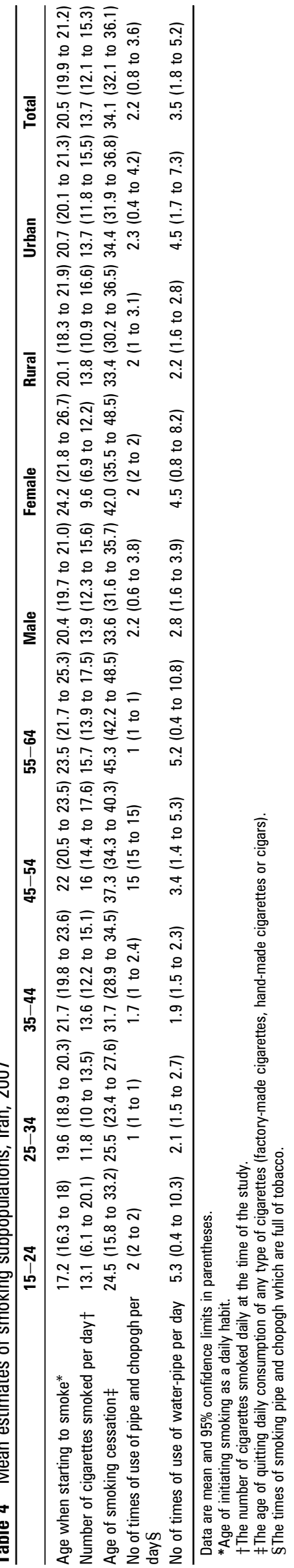




\section{What is already known on this subject?}

- Developing nations experience a disproportionate share of the global tobacco burden. Estimates for low and middle-income countries are $49 \%$ for men and $8 \%$ for women. Up-to-date national estimates of the tobacco burden in Iran do not exist.

1999 in all studied strata (age, sex and residential area). Further, comparing our results with those reported by Azizi et a ${ }^{11}$ for Tehran $(10.8 \%)$, no statistically significant change has occurred from 2000 to 2007 according to $95 \%$ CIs. In addition, no significant change in current tobacco smoking prevalence was found when our estimates were compared to a subnational study (12.6\%; 26\% in males and $1.4 \%$ in females) conducted in 1994 on the adult population aged 19-70 in an urban area in Iran. ${ }^{12}$

Among European countries the lowest rate of daily smoking in adult men is in Sweden (14.9\%) and the highest rate is in Russia $(65 \%){ }^{3}$ In general, the prevalence rates are lower in western European countries (below 30\%). ${ }^{13}$ The prevalence of daily cigarette smoking among Iranian men is higher than in Sweden $(21.4 \%$ vs $14.9 \%)$ but lower than those in western European nations. The smoking prevalence among women in Iran is much lower than in all European countries except Azerbaijan $(0.4 \%){ }^{13}$ The daily smoking prevalence rate is equal for men in the USA (20.9\%) and in Iran; but it is much higher among adult females in the USA $(15.5 \%){ }^{3}$

The prevalence of daily smoking among Iranian men is lower than in Japan (41\% for males and $11.1 \%$ for females) and China (57.1\% for males and $3.4 \%$ for females). The prevalence of smoking among females in Iran is the same as in China and is lower than in Japan; however, the burden of smoking among Chinese women is noticeably higher because of the large size of population. ${ }^{3}$

Another important comparison is among our neighbouring countries and those around Persian Gulf. For men, prevalence rates in Iran are similar to other countries in the region excluding Pakistan (28.9\%) and Turkey (45.1\%), which have higher estimates. Iran is more populated than most of its neighbouring countries and this can make the burden of smoking higher in Iran. The prevalence of smoking among adult females is higher than in Iraq (1.6\%), and United Arab Emirates (1.2\%) but lower than in Turkey $(14.8 \%)$ and equal to other countries in this region. ${ }^{3}$

\section{CONCLUSION}

Developing nations experience a disproportionate share of the global tobacco burden. The results of this study provide baseline information to monitor tobacco control strategies. The prevalence of daily smoking in Iran $24.3 \%$ in males and $2.9 \%$ in females) is not as high as in most developed nations. Furthermore, the prevalence of smoking in Iran did not increase over the past decades. Nevertheless, because of the escalating size of the

\section{What this study adds}

The results of this study provide baseline information to monitor public health strategies for fighting tobacco abuse. The prevalence of daily smoking in Iran (24.3 in males and 2.9 in females) is not as high as in developed nations. Further, the prevalence of smoking in Iran did not increase over the past two decades. Nevertheless, because of the escalating size of the Iran population, the smoking burden will likely rise in the future.

Iranian adult population, the smoking burden will likely rise in future.

Acknowledgements The data for this study were extracted from the dataset of third round of non-communicable disease risk factor survey/surveillance in Iran (2007) which was conducted by the Center for Control and Management of Diseases (Ministry of Health, Iran) in cooperation with 41 medical universities of the country.

Contributors AM, RG and MA drafted the manuscript and provided for revisions. MH, FA and AE participated in data collection. Data analyses were performed by AM. All the authors participated in the literature review and data interpretation, and reviewed final and revised versions.

Funding This study was supported by the Iran Center for Disease Control and Management; and the Ministry of Health of Iran.

Competing interests The authors declare no competing interests.

Ethics approval This survey was approved by the ethics committee of the Center for Disease Management of Iran.

Provenance and peer review Not commissioned; externally peer reviewed.

\section{REFERENCES}

1. Jha P, Chaloupka FJ. Tobacco control in developing countries. Oxford, UK: Oxford University press, 2000

2. Mackay J, Eriksen M. The Tobacco Atlas. Geneva: World Health Organization, 2002

3. WHO Report on the Global Tobacco Epidemic, 2008. The MPOWER package. Geneva: World Health Organization, 2008.

4. Peto R, Lopez AD, Boreham J, et al. Mortality from smoking in developed countries 1950-2000; indirect estimation from National Vital Statistics. Oxford, UK: Oxford University Press, 1994.

5. Slama K. Current challenges in tobacco control. Int J Tuberc Lung Dis 2004:8:1160-72.

6. Dunn A, Zeine L. Health effects of exposure to environmental tobacco smoke. Sacramento, CA: California Environmental Protection Agency, 1997.

7. Cook DG, Strachan DP. Health effects of passive smoking-10: Summary of effects of parental smoking on the respiratory health of children and implications for research. Thorax 1999;54:357-66.

8. WHO. STEPwise approach to surveillance (STEPS). http://www.who.int/chp/steps/ en/ (accessed Oct 2008)

9. Sarraf-Zadegan N, Boshtam M. Tobacco use among Iranian men, women and adolescents. Eur J Public Health 2004;14:76-8.

10. Mohammad K, Noorbala AA, Majdzadeh SR, et al. Trend of smoking prevalence in Iran from 1991 to 1999 based on two national health survey. Hakim Res J 2001:4:297-0.

11. Azizi F. Tehran lipid and glucose study tehran, endocrine research center, Shaheed Beheshti university of medical sciences. J Res Med 2003:27:47-52.

12. Sarraf-Zadegan N, Boshtam $M$, Rafiei $M$. Risk factors for coronary artery disease in Isfahan, Iran. Eur J Public Health 1999;1:20-6.

13. World Health Organization. The European tobacco control report, 2007. Geneva: WHO, Regional Office for Europe, 2007 http://www.euro.who.int/document/e89842. pdf (accessed Dec 2007). 